\title{
Over 10 years follow-up of Coats' disease in adulthood
}

This article was published in the following Dove Press journal:

Clinical Ophthalmology

7 December 2011

Number of times this article has been viewed

\section{Tatsuro Otani' \\ Kanako Yasuda' \\ Naoko Aizawa ${ }^{2}$ \\ Fumiaki Sakai ${ }^{3}$ \\ Toru Nakazawa ${ }^{2}$ \\ Masahiko Shimura' \\ 'Department of Ophthalmology, NTT East Japan Tohoku Hospital, ${ }^{2}$ Department of Ophthalmology, Tohoku University School of Medicine, ${ }^{3}$ Heisei Ophthalmic Associates P.O., Sendai, Miyagi, Japan}

Correspondence: Masahiko Shimura Department of Ophthalmology, NTT East Japan Tohoku Hospital, 2-29-I, Yamato-machi, Wakabayashi, Sendai, Miyagi 984-8560, Japan

$\mathrm{Tel}+8 \mathrm{I} 22236583 \mathrm{I}$

Fax +8I 222365484

Email masahiko@vılol.vaio.ne.jp
Abstract: Coats' disease diagnosed in adulthood is rare; therefore, the treatment options and longer clinical course are not well established. We report on two cases of adult onset Coats' disease, which have been observed for more than 10 years after conventional treatment. In the first case, a 76-year-old man with 9 years of diabetic retinopathy noticed a visual field defect in his left eye. Yellowish subretinal exudation with serous retinal detachment in his superior peripheral retina, and telangiectatic vessels with fluorescein leakage, numerous microaneurysms, and areas of capillary nonperfusion observed in a fluorescein angiography indicated adult Coats' disease, and retinal photocoagulation was applied. Within 1 year, subretinal exudation was regressed and visual acuity was improved from 20/50 to 20/20, and was maintained for the next 11 years. In the second case, a 71-year-old man presented with decreased vision in his right eye. The fundus of his right eye showed multiple telangiectasic vessels and subretinal exudates extended to the fovea, which is diagnosed as adult Coats' disease. Despite retinal photocoagulation, an increase of exudation and an enlargement of retinal detachment was observed within 1 month, and subsequently, additional treatment of cryotherapy was performed. Two months after these therapies, the exudation was regressed without retinal detachment, and visual acuity was improved to 20/200 which was maintained for the next 10 years. Even with adult Coats' disease, conventional therapies of retinal photocoagulation and cryotherapy are effective and are the initial choice for improving or maintaining visual function.

Keywords: adult onset, Coats' disease, treatment, follow-up

\section{Introduction}

Coats' disease was first described by George Coats in $1908,{ }^{1}$ and is characterized by the formation of telangiectatic and aneurismal changes of the retinal vessels and is associated with a large amount of yellowish intraretinal and subretinal exudates. ${ }^{2}$ It is predominantly unilateral occurring mostly in young males under the age of 5 years, and can cause severe visual loss resulting from exudative retinal detachment. ${ }^{3}$

Less commonly, Coats' disease presents in adulthood. The mean age at the time of diagnosis is approximately 50 years, and it progresses at a slower rate, but with similar features. ${ }^{4}$ Although various methods have been employed to treat Coats' disease, including diathermy, retinal photocoagulation, cryotherapy, and vitreous surgery to elucidate the abnormal vessels, thereby minimizing exudation, the prognosis of visual function remains unsatisfactory. ${ }^{5}$ However, only a few cases of the clinical course of adult Coats' disease after treatment have been reported.

In this article, we report the long-term follow-up of two cases of rapidly progressive Coats' diseases diagnosed over the age of 60 years with more massive and/or extensive 
lipid exudates close to the macular area. In these cases successful treatment with conventional therapy of retinal photocoagulation and/or cryoretinopexy improved Coats' disease and allowed the patients to keep their visual function for more than 10 years.

\section{Case I}

A 76-year-old man noticed a visual field defect and decreased vision of 20/50 in his left eye. He had a history of diabetic retinopathy diagnosed 9 years before (at age of 67) and focal retinal photocoagulation had been applied and observed every year without any visual disturbance. At the initial visit (Figure 1A), fundus examination revealed thick subretinal exudates extended to and threatening the fovea, and fluorescein angiography (FA) showed telangiectatic vessels with fluorescein leakage, numerous microaneurysms, and areas of capillary nonperfusion. An optical coherence tomography (OCT) indicated an exudative retinal detachment, which is a hallmark of advanced Coats' disease. ${ }^{6}$ He was diagnosed as having Coats' disease at age 76. Laser photocoagulation was applied to the vascular lesion, and then subretinal exudates were gradually regressed. At 1 year after the treatment, visual acuity improved to 20/20, and abnormal retinal vessels and subretinal exudates were significantly regressed. FA indicated marked reduction of fluorescein leakage from abnormal retinal vessels compared to the previous status, and OCT presented a disappearance of exudative retinal detachment (Figure 1B).

At a follow-up 11 years after the treatment for Coats' disease, subretinal exudation was minimized with retinal atrophy and visual acuity in his left eye remained at 20/20 (Figure 1C).

\section{Case 2}

A 71-year-old man was referred to our hospital due to visual impairment in his right eye despite successful cataract surgery. He noticed visual disturbance 3 years before the surgery. At his initial visit, the best-corrected visual acuity of his right eye was 12/20 and the fundus examination and FA revealed severe lipid exudation and multiple telangiectatic vessels found on the overall retina with exudative retinal detachment (Figure 2A). A clinical diagnosis of Coats' disease was made and laser photocoagulation was applied to all telangiectatic vessels. However, it was difficult to inhibit aggravation of the disease condition, and visual acuity worsened to $8 / 200$. Thus, additional treatment of cryotherapy
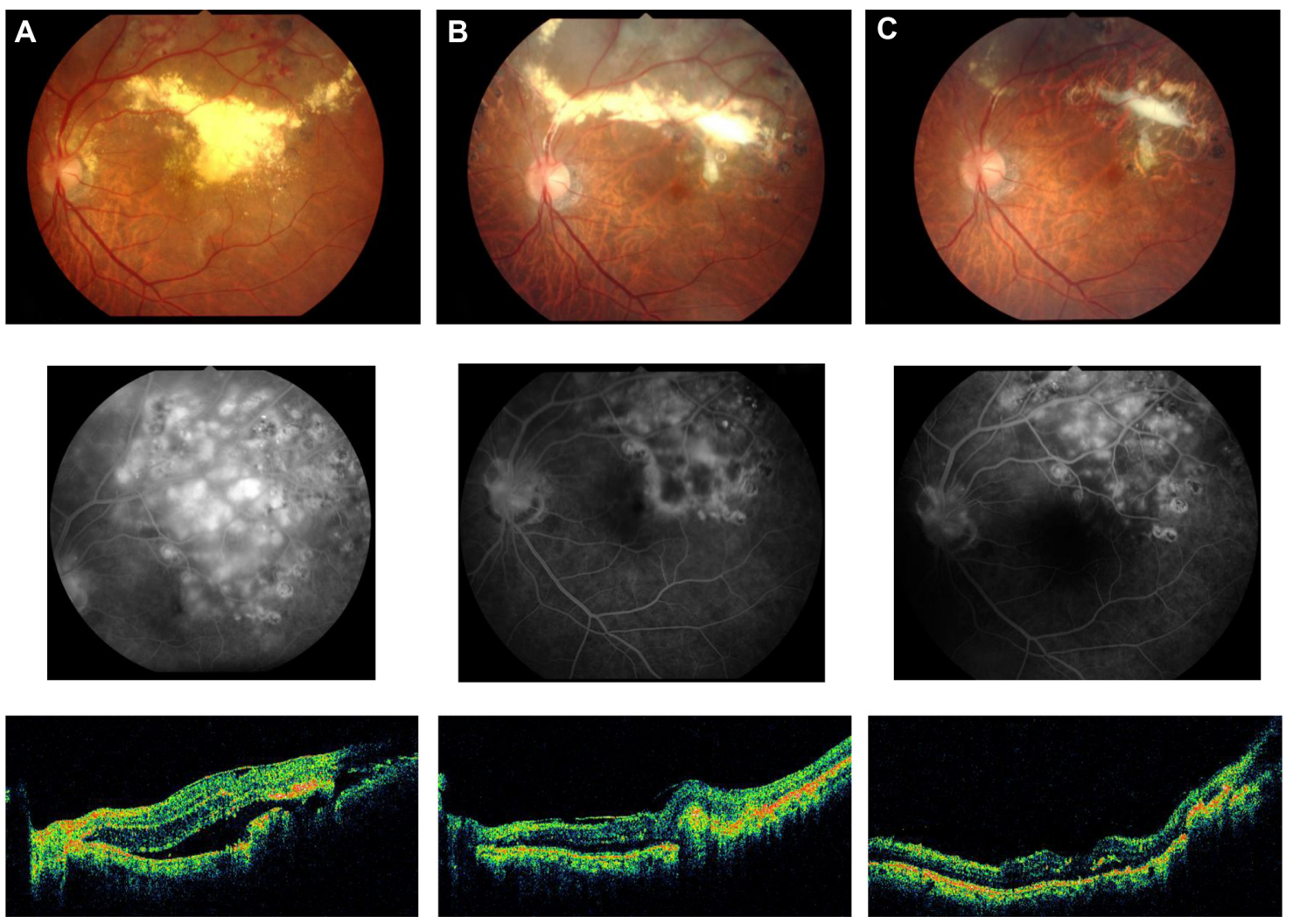

Figure I Color fundus photograph (upper panel), corresponding fluorescein angiography (middle), and optical coherence tomography (lower) of the left eye in patient \#I with adult Coats' disease: (A) at the initial visit; (B) I year after treatment of retinal photocoagulation; (C) II years after treatment. 

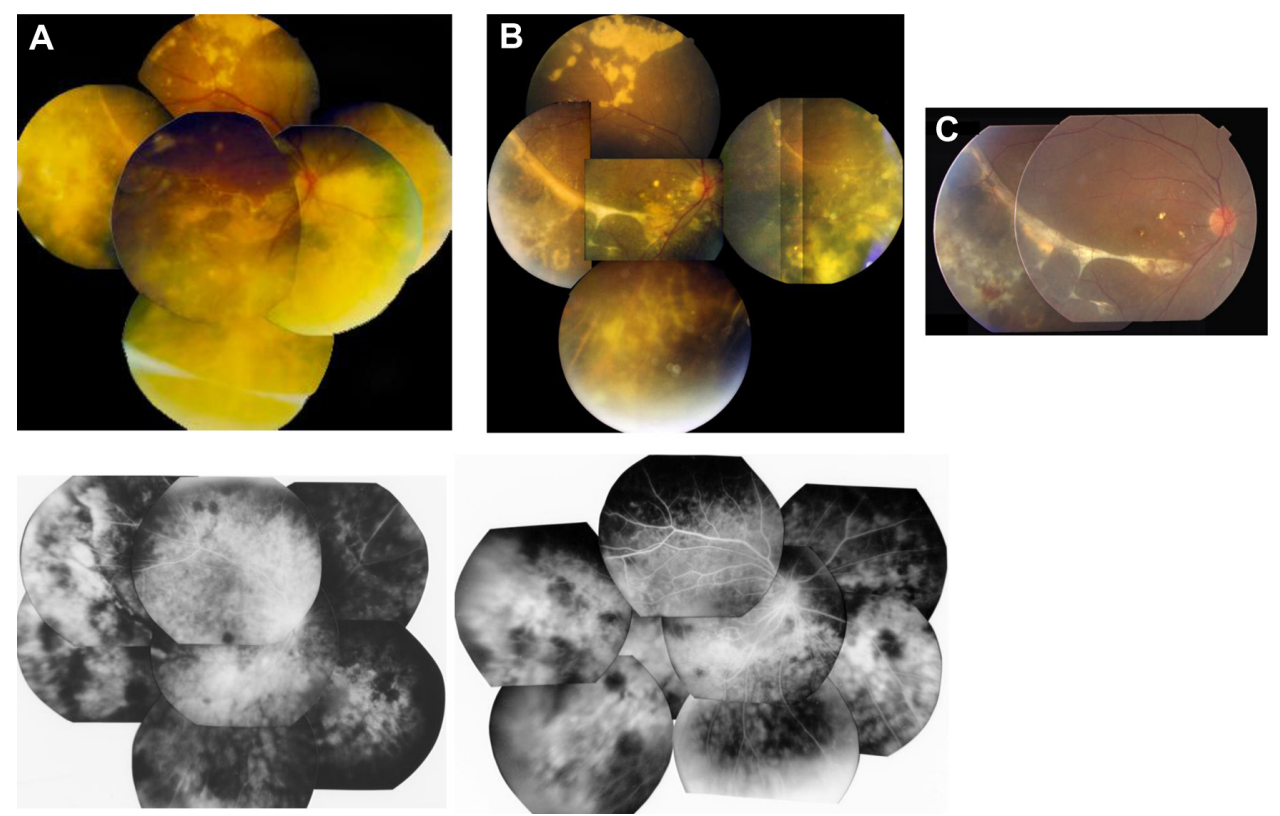

Figure 2 Color fundus photograph (upper panel), corresponding fluorescein angiography (lower) of the right eye in patient \#2 with adult Coats' disease. (A) At the initial visit; (B) 3 months after treatment of retinal photocoagulation and cryotherapy; (C) 10 years after treatment (FA image not available).

was performed 1 month after the photocoagulation. Three months after that, lipid exudation was settled with the disappearance of exudative detachment, and visual acuity improved to 20/200 (Figure 2B). At a follow-up 10 years after the treatment, subretinal exudation was diminished and the right VA remained at 20/200 (Figure 2C).

\section{Comments}

According to several studies, ${ }^{2-7}$ the progression of Coats' disease is relatively slow in older children or adults, and it shows indolent clinical features. The adult cases are often asymptomatic and the extent of exudation and retinal detachment tends to be mild and limited; however, the involvement of the macula as a result of subretinal exudates or exudative retinal detachment can produce poor visual acuity. Although diabetes mellitus was associated with case \#1, clinical features and clinical course were typical Coats' disease. Visual prognosis in the long timespan of the follow-up (more than 10 years) showed poor results including visual acuity change from $20 / 40$ to $4 / 200$ over 15 years, and 20/30 to $20 / 70$ over 11 years. ${ }^{4}$

Although clinical treatments for adult onset Coats' disease are not well established due to the low number of cases, ablation of abnormal retinal vessels either by laser photocoagulation or by cryotherapy are adopted in clinical situations. In this case report, intensive therapy of photocoagulation and cryoretinopexy to vascular lesions was effective enough to reduce or remove the exudative changes, and more importantly, have suppressed the worsening or recurrence of exudation for more than 10 years. Thus, these therapies were able to either improve or stabilize vision in both cases. Laser photocoagulation in the early stages, either alone, or in combination with cryotherapy, has proven to be effective especially in cases of the young. In case \#1, prompt photocoagulation after decreased vision, similar to treatment in Coats' disease of the young, resulted in a good visual prognosis for a long time, which indicated that prompt treatment and careful follow-up in adult-onset Coats' disease are crucial for the preservation of visual function. Even in case \#2, although conventional therapies were effective for inhibition of worsening visual function, final visual acuity of 20/200 was not satisfactory, and earlier treatment before vision deteriorates might lead to better visual prognosis. In addition, more powerful treatment options such as recently successful treatments using a combination therapy of photodynamic therapy (PDT) and intravitreal bevacizumab injection (IVB) for severe adult Coats' disease have been reported for a better visual prognosis. ${ }^{8}$ Unfortunately, both PDT and IVB were not available in 1997, but in the future, such a treatment option may help patients similar to those in case \#2.

In conclusion, we have presented two cases of rapidly progressive adult onset Coats' disease with exudative retinal detachment and massive and/or extensive lipid exudates. For these cases, conventional therapies were confirmed as effective and useful treatments to maintain visual function 
not only for the short term but also for longer clinical courses of more than 10 years.

\section{Disclosure}

The authors report no conflicts of interest in this work.

\section{References}

1. Coats G. Forms of retinal disease with massive exudation. $R$ Lond Ophthal Hosp Rev. 1908;17(3):440-525.

2. Rubin MP, Mukai S. Coats' disease. Int Ophthalmol Clin. 2008;48(2): $149-158$.

3. Shields JA, Shields CL, Honavar SG, Dermici H. Clinical variations and complications of Coats disease in 150 cases: the 2000 Sanford Gifford Memorial Lecture. Am J Ophthalmol. 2001;131(5):561-571.
4. Smithen LM, Brown GC, Brucker AJ, Yannuzzi LA, Klais CM, Spaide RF. Coats' disease diagnosed in adulthood. Ophthalmology. 2005;112(6):1072-1078

5. Shields JA, Shields CL, Honavar SG, Dermici H, Cater J. Classification and management of Coats disease: the 2000 Proctor Lecture. Am J Ophthalmol. 2001;131(5):572-583.

6. Jones JH, Kroll AJ, Lou PL, Ryan EA. Coats' disease. Int Ophthalmol Clin. 2001;41(4):189-198.

7. Shields JA, Shields CL. Review: coats disease: the 2001 LuEsther T. Mertz lecture. Retina. 2002;22(1):80-91.

8. Kim J, Park KH, Woo SJ. Combined photodynamic therapy and intravitreal bevacizumab injection for the treatment of adult Coats' disease: a case report. Korean J Ophthalmol. 2010;24(6):374-376.
Clinical Ophthalmology

\section{Publish your work in this journal}

Clinical Ophthalmology is an international, peer-reviewed journal covering all subspecialties within ophthalmology. Key topics include: Optometry; Visual science; Pharmacology and drug therapy in eye diseases; Basic Sciences; Primary and Secondary eye care; Patient Safety and Quality of Care Improvements. This journal is indexed on

\section{Dovepress}

PubMed Central and CAS, and is the official journal of The Society of Clinical Ophthalmology (SCO). The manuscript management system is completely online and includes a very quick and fair peer-review system, which is all easy to use. Visit http://www.dovepress.com/ testimonials.php to read real quotes from published authors. 